\title{
Mixing-up research methods: A recipe for success or disaster?
}

\author{
Nicola Ann Plastow BSc OT (UCT), MSc Prof Health Studies (University of Leeds, UK), PG Cert Learning \\ and Teaching in Higher Education (Brunel University, London), PhD Clinical Sciences (Brunel University, \\ London) \\ Senior Lecturer, Division of Occupational Therapy, Faculty of Medicine and Health Sciences, Stellenbosch University
}

The increase in the number of occupational therapists training and doing research at undergraduate and post-graduate degree level has led to an exciting growth in research capacity within our profession. My experiences of doing research and in supervising students have raised questions about which methodologies students should be able to apply at the beginning of their research careers. In this opinion piece I argue that concurrent mixed-methods research designs across more than one research paradigm are inappropriate for undergraduate and Masters-level research, because of issues with integration, transparency, and the time taken to develop the sufficient research expertise required for this methodology.

Keywords: Mixed-methods, study design

\section{INTRODUCTION}

Since I was an undergraduate student, more than 15 years ago, there has been a noticeable increase in the number of occupational therapists training and doing research at both undergraduate and post-graduate level across South Africa. This signals a very exciting growth in research capacity within the profession. As a supervisor, one of the questions I need to consider is which research methodologies students are able to apply effectively to answer their research questions, given their level of research training and experience. My experience of supervising undergraduate and Masters students' research, and of doing a PhD using concurrent mixed methods, has led me to conclude that concurrent mixed-methods research designs that draw from different research paradigms are inappropriate for undergraduate and post-graduate research students. Instead, these types of designs should only be used by experienced researchers working in teams.

\section{THE INGREDIENTS FOR MIXED-METHODS RESEARCH}

Mixed-methods research is usually understood as a combination of qualitative and quantitative approaches'. However, mixed-methods research can also include the mixing of qualitative methods only, or quantitative methods only ${ }^{1,2}$. In the fourth edition of his landmark text on mixed-methods research, Creswell ${ }^{3}$ identifies three different types of mixed-methods studies: convergent, explanatory sequential, and exploratory sequential. The focus of this opinion piece is on convergent designs, which have also been labelled as concurrent, parallel, and simultaneous studies, in the literature.

\section{Recipe for Success}

Concurrent research designs involve a single data collection episode incorporating various qualitative and / or quantitative strategies to answer a research question ${ }^{2,4}$. Using Morse's ${ }^{5}$ taxonomy, the research design for a hypothetical concurrent study is illustrated in Figure $I$. The parallel rather than sequential nature of the different study components means data are collected at one point in time. The difference in relative importance of each component is also illustrated. In concurrent mixed-methods designs, one type of data is usually nested within another predominant data collection procedure ${ }^{6}$. Morse ${ }^{5}$ refers to the predominant method as the 'base study' and the nested method as the 'supplemental study'. The base study determines the overall theoretical drive of the study, while the supplemental study provides information that cannot be gathered from the base study data ${ }^{5}$. In the illustrated study, qualitative strategies form the base study, while quantitative and $Q$ methodology strategies are supplemental. The overlap between the three study components in Figure $I$ also illustrates that integration can occur at the data collection, data analysis, and interpretation stages.

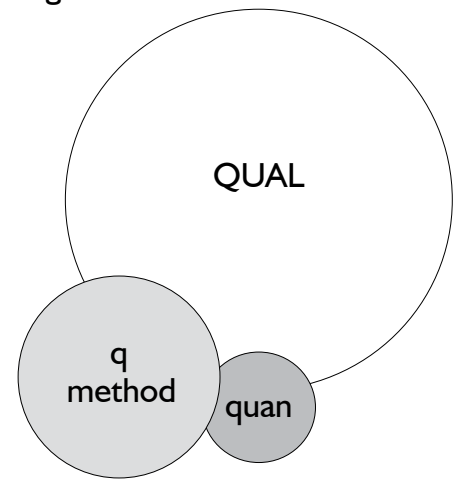

Figure I: Components of a Concurrent Mixed-methods Study

One of the advantages of mixed-methods is that the strengths of one research method compensate for the weaknesses of another ${ }^{2}$. Triangulation also incorporates many different perspectives, helps to avoid the biases of a single method or researcher, and completes the links between observation and theory construction ${ }^{7}$. The validity of quantitative studies, and rigour and trustworthiness of qualitative studies can also be improved by verifying and elaborating findings from one component with findings from another component ${ }^{2,4}$. Indeed, other qualitative researchers have talked about how a combining visual methods with in-depth interviews leads to longer, more in-depth, and more focussed interviews, in comparison to the semi-structured interviews ${ }^{8,9}$. Using more than one measure of a particular construct, and using a variety of statistical tests, also improves the validity of quantitative studies. 


\section{Why the Recipe is not Flop-proof}

While mixing methods within one research paradigm has many advantages, the potential pitfalls of mixing methods across paradigms outweigh the advantages. For this reason, I would argue that concurrent mixed-methods research designs across more than one research paradigm are inappropriate for student research. In considering why the disadvantages of concurrent mixed-methods research outweigh these advantages I have considered the difficulty of integrating analyses that are reported by other researchers ${ }^{10,11,12}$. I have also drawn on Bryman, Becker, and Sempik's ${ }^{13}$ research that describes four quality criteria for mixed methods studies. These criteria are based on an online survey completed by $25 \mathrm{I}$ social policy researchers, and follow up telephone interviews with 28 of these respondents. Two of the criteria are that the researcher should be transparent about the way the study was conducted, and that the findings should be properly integrated ${ }^{13}$.

One issue I have faced with a concurrent mixed-methods design is that substantial expertise is needed in different research paradigms to avoid making basic mistakes. For example, in my PhD study, I used $Q$ methodology as part of a mixed-methods research design. Differences between the abductive and interpretavist approach to $\mathrm{Q}$ methodology I planned to use in my study, and the deductive and positivist approach to $\mathrm{Q}$ methodology used in the United States, meant I realised after data collection that it was inappropriate to correlate $\mathrm{Q}$ sort statements with quantitative data. I also used quantising to convert qualitative findings into quantitative variables. I found categorising the qualitative data uncomfortable and difficult. On reflection, this discomfort was because of a clash between the relativist and realist assumptions I took within different research components. I believe these basic mistakes happened because I was trying to gain expertise in too many different methodologies within different research paradigms at the same time.

Another issue is that fully integrating different concurrent components makes it difficult to maintain transparency in data analysis. In a mixed-methods study, the advice is to write the results of each component as a separate chapter. The reality of concurrent mixedmethods research however is that it is a complex and often messy iterative process of moving back and forth between the findings over a long period of time. Although students may carefully log each analytic step when fully immersed in the data analysis, maintaining an audit trail becomes more difficult once writing up begins. The complexity of a concurrent mixed-methods research design may explain why a methodological review of mixed-methods in health services research found concurrent designs were the least common, in comparison to sequential mixed methods designs ${ }^{14}$. Based on my experience, transparency is much more difficult to maintain in a concurrent mixed methods study. Consequently, parallel and sequential mixed methods are likely to produce more transparent studies.

Concurrent mixed-methods studies take much longer, and may be of a lower quality than a single-method study, for a number of reasons: i) Time is needed to develop new data sets, for example in the quantitisation of qualitative data. ii) Students need to develop data analysis skills for each type of data. Both undergraduate and post-graduate students are only at the beginning of their research training. To expect them to develop competency in a number of different types of data analysis is, in my view, an unreasonable expectation. iii) Different writing styles are needed for different types of data. Fetters ${ }^{15}$ describes three different ways in which mixed-methods studies can be written up. Nevertheless, he does not address how a student should switch easily from the more narrative style use in qualitative studies to the abbreviated style common in quantitative studies. iv) It takes time to integrate and interpret the multiple data sets during each of the phases of analysis.

\section{CONCLUSION}

I have reached three conclusions about concurrent mixed methods research: Firstly, concurrent mixed methods studies should not include more than two methods from different research paradigms. Secondly, the quality of each component is lower and time taken to complete the study is higher than a single research paradigm, or a sequential mixed methods design. Thirdly, a concurrent mixed methods study situated in more than one research paradigm is not the best method for a time-limited project by novice researchers, including undergraduate and post-graduate students. Instead, we should be offering our bright and competent students research projects that give them the opportunity to develop an in-depth understanding of the complexities of research within one paradigm.

\section{ACKNOWLEDGEMENTS}

The $\mathrm{PhD}$ study mentioned in this opinion piece was generously funded by the British Geriatrics Society / Dunhill Medical Trust Research Fellowship. My thanks are extended to Prof Mary Gilhooly and Dr Anita Atwal for their supervision of this research.

\section{REFERENCES}

I. Sandelowski M. Unmixing mixed-methods research. Research in Nursing \& Health, 20I4; 37(I): 3-8.

2. Creswell JW, Plano Clark VL, Gutmann ML, Hanson WE. Advanced mixed methods research designs. In: A Tashakkori, C Teddlie, eds. Handbook of mixed methods in social and behavioural research. Thousand Oaks: SAGE Publications, 209-240, 2003.

3. Creswell JW. Research design: Qualitative, quantitative, and mixed methods approaches. $3^{\text {rd }}$ ed. Thousand Oaks: SAGE Publications, 2013.

4. Johnson RB, Onwuegbuzie AJ, Turner LA. Towards a definition of mixed methods research. Journal of Mixed Methods Research, 2007 . I(2): II I-I33.

5. Morse JM. Principles of mixed method and multimethod research design. In: A Tashakkori, C Teddlie, eds. Handbook of mixed methods in social and behavioural research. Thousand Oaks: SAGE Publications, 2003: 189-208.

6. Creswell JW. Research Design: Qualitatiive, Quantitative, and Mixed Methods Approaches. $2^{\text {nd }}$ ed. Thousand Oaks: SAGE Publications, 2003.

7. Denzin NK. The research act. New York: McGraw-Hill, 1978.

8. Oliffe JL, Bottorff JL. Further than the eye can see? Photo elicitation and research with men. Qualitative Health Research, 2007; 17(6): 850-858.

9. Van Auken PM, Frisvoll SJ, Stewart SI (20I0) Visualising community: using participant-driven photo-elicitation for research and application. Local Environment, I5(4), 373-388.

10. Bryman A. Barriers to integrating quantitative \& qualitative research. lournal of Mixed Methods Research, 2007; I(I): 8-22.

I I. Moen J, Antonov K, Nilsson JL, Ring L. Interaction between participants in focus groups with older patients and general practitioners. Qualitative Health Research, 2010; 20(5): 607-616.

12. O'Cathain A, Murphy E, Nicholl J. Three techniques for integrating data in mixed methods studies. British Nursing Journal, 20 I0; 34I.

13. Bryman A, Becker S, Sempik J. Quality criteria for quantitative, qualitative and mixed methods research: A view from social policy. International Journal of Social Research Methodology, 2008; I I (4): $26 \mathrm{I}-76$.

14. Ostlund U, Kidd L, Wengstrom Y, Rowa-Dewar N. Combining qualitative and quantitative research within mixed method research designs: A methodological review. International Journal of Nursing Studies, 201 I; 48(3): 369-383.

15. Fetters MD, Curry LA, Creswell JW. Achieving integration in mixed methods designs - principles and practices. Health Services Research, 2013; 48(6): 2134-2156.

Corresponding Author

Nicola Plastow

nap@sun.ac.za 